\title{
Neuroscience-based Tests for Assessing Cognitive Changes in Normal Aging and in the Prodromal Phase of Alzheimer's Disease
}

\author{
Diana S. Woodruff-Pak • Jacob Raber
}

Published online: 25 January 2012

(C) Springer Science+Business Media, LLC 2012

\begin{abstract}
Slow decline in cognition is key to the clinical diagnosis of Alzheimer's disease (AD). This diagnosis relies on screening tests insensitive to detection of prodromal $\mathrm{AD}$, which occurs years before the appearance of clinical symptoms. Neuroscience-based tests of eyeblink classical conditioning, spatial navigation, and object recognition are associated with synaptic-level function. They show promise in detecting early changes in AD-impacted memory circuits. Eyeblink conditioning engages synapses dependent upon nicotinic acetylcholine receptors and medial septal cholinergic input to the hippocampus. Spatial navigation and object recognition engage perforant pathway entorhinal cortical input to the hippocampus. Synapses in these circuits are among the earliest impacted by beta amyloid. These three translational tests are well characterized in normal aging and $\mathrm{AD}$ in humans and pertinent animal models, including organisms expressing the $\mathrm{AD}$ risk factor apolipoprotein E4. They may detect cognitive decline in prodromal AD and prove useful for population screening and evaluation of therapeutic interventions.
\end{abstract}

\footnotetext{
D. S. Woodruff-Pak $(\bowtie)$

Departments of Psychology, Neurology, and Neuroscience

Program, Temple University,

1701 North 13th Street/Weiss Hall,

Philadelphia, PA 19122, USA

e-mail: pak@temple.edu

D. S. Woodruff-Pak

Department of Behavioral Neuroscience,

Oregon Health \& Science University,

Portland, OR, USA

J. Raber

Departments of Behavioral Neuroscience and Neurology,

Oregon Health \& Science University,

Portland, OR, USA
}

Keywords Acetylcholine $\cdot$ Animal models $\cdot$ Associative learning $\cdot$ Beta amyloid $\cdot$ Cholinergic $\cdot$ Delay classical conditioning paradigm $\cdot$ Entorhinal cortex $\cdot$ Eyeblink classical conditioning $\cdot$ Long-term potentiation $\cdot$ Medial septum · Memory Island · Morris water maze $\cdot$ Neurofibrillary tangles · Nicotinic acetylcholine receptors · Novel Image Novel Location · Object recognition · Perforant pathway . Alzheimer's disease · Preclinical Alzheimer's disease . Preclinical research · Spatial learning · Spatial navigation . Synapse $\cdot$ Tau

\section{Introduction}

Gradual memory loss and impairment in other cognitive functions used in the clinical diagnosis of Alzheimer's disease $(A D)[1,2]$ occur after neuropathology has caused irreversible deterioration in the brain [3]. Recent research advances led to recognition of a prodromal phase of $\mathrm{AD}$ that occurs years before the appearance of clinical symptoms $[4$, $5 \bullet \bullet, 6 \bullet \cdot$. Biomarkers identifiable in the cerebral spinal fluid $(\mathrm{CSF})$ and brain demonstrate that beta amyloid $(\mathrm{A} \beta)$ aggregation and deposition increase slowly from cognitive normality in healthy adults to moderate severity in patients with clinically diagnosed $\mathrm{AD}$. In humans, a slow accumulation of $\mathrm{A} \beta$ in the brain precedes cognitive impairment as measured by the brief neuropsychological screening tests that are currently used. These early changes are exacerbated in the presence of the apolipoprotein E (APOE) $\varepsilon 4$ allele encoding apolipoprotein E4 (apoE4). However, longitudinal data indicate that cognitive decline is only weakly related to change in $\mathrm{A} \beta$ burden in the brain [7•]. Furthermore, the duration of the disease appears to be unaffected by genetic factors such as early onset in $A P O E \varepsilon 4$ carriers [8••]. 
The largest known genetic risk factor for sporadic $\mathrm{AD}$ is the $\varepsilon 4$ allele of the apolipoprotein E gene [9]. The $A P O E \varepsilon 4$ allele markedly increases AD risk and decreases age of onset, likely through its strong effect on the accumulation of $A \beta$ by impairing $A \beta$ clearance from the brain [10*0]. $A P O E \& 4$ carriers in the age decades of the 50 s and 60 s have more rapid memory loss and reduced learning efficiency than matched $A P O E \& 4$ noncarriers. Clinically healthy $A P O E \& 4$ carriers diverge from noncarriers before the age of 60 years [11].

The clinical assessment of cognitive changes in $\mathrm{AD}$ has traditionally relied on brief cognitive screening tests that are not sensitive to the earliest cognitive changes. Detecting these early cognitive changes before clinical AD symptoms develop is vital for the development and eventual success of therapeutic interventions. Biomarkers can involve invasive (eg, spinal tap) or expensive (positron-emission tomography [PET]) hospital-based procedures. Therefore, population-based cognitive screening with simpler, more accessible techniques is desirable as an initial step to detect prodromal $\mathrm{AD}$ and enhance the ability to treat the disease successfully before irreversible changes in the brain ensue.

Neuroscience-based translational cognitive tests of eyeblink classical conditioning, object recognition, and spatial navigation show promise in detecting early changes associated with risk factors of developing age-related cognitive decline in the absence of frank dementia and AD. Extensive knowledge on the neurobiological substrates of eyeblink classical conditioning, spatial navigation, and object recognition has been developed in nonhuman mammalian species and extended to humans. These tests are also well characterized in normal aging and in animal models of age-related cognitive decline and $\mathrm{AD}$. These three neuroscience-based tests detect disruption in synapses in brain circuits impaired in prodromal AD.

For some years, impairment in acetylcholine neurotransmission was a major focus in AD research [12-14], and early treatment strategies aimed to ameliorate cholinergic function. More recently, studies indicate that neuron loss in the forebrain cholinergic system is associated with end-stage $\mathrm{AD}$, whereas upregulation in the septohippocampal system occurs in the prodromal phase $[15,16]$. Distinct $A \beta$ oligomers and fibrils induce loss of nicotinic acetylcholine receptors (nAChRs) and interference with cholinergic neurotransmission [17•]. Disruption of the septohippocampal cholinergic system impairs delay eyeblink classical conditioning [18]. Lower numbers of nAChRs also have been associated with poor conditioning $\left[19,20^{\bullet}\right]$ as has knock out of $\alpha 7$ nAChRs [21]. Impairment resulting from septohippocampal cholinergic perturbations and loss of nAChRs are features of prodromal $\mathrm{AD}$ that may be detected by eyeblink classical conditioning.

The principal source of cortical input to the hippocampal formation is the perforant pathway, a large neuronal projection arising from layer II of the entorhinal cortex. Pathological changes in the perforant pathway occur early in disease progression in human $\mathrm{AD}$ as shown in histopathological [22, 23] and neuroimaging studies [24, 25]. Amyloid imaging demonstrates the selective vulnerability of the perforant pathway circuitry in human $\mathrm{AD}$. Brain magnetic resonance imaging (MRI) and $\left[{ }^{11} \mathrm{C}\right]$ Pittsburgh Compound $\mathrm{B}$ (PiB)-PET scans in 93 healthy elderly patients and 43 patients with mild cognitive impairment demonstrated that subtle deficits in episodic memory were closely related to $A \beta$ deposition in the medial temporal neocortex, loss of white matter volume in the perforant pathway, and shrinkage of hippocampal volume [26].

Negative amyloid scans indicate the absence of AD with high accuracy, but some healthy elderly volunteers also have positive amyloid scans [27] in the seeming absence of cognitive impairment [28]. The value of biomarkers predicting conversion to clinical $\mathrm{AD}$ has limitations in the absence of tests sensitive to subtle cognitive changes in prodromal $\mathrm{AD}$. Investigations using animal models of $\mathrm{AD}$ also indicate that the entorhinal cortex and perforant pathway input to the hippocampus are among the earliest affected and most vulnerable regions of $A \beta$ pathology [29-31]. Spatial ability likely becomes affected in prodromal $\mathrm{AD}$ because $\mathrm{A} \beta$ selectively disrupts perforant pathway input to hippocampus from the entorhinal cortex. Together with the fact that eyeblink classical conditioning is sensitive to alterations in the cholinergic septohippocampal system and impairment and loss of nAChRs, the object recognition, spatial navigation, and eyeblink conditioning tests may help to identify at-risk individuals in the prodromal phase of $\mathrm{AD}$ and augment predictions about which biomarker-positive individuals are most likely to develop clinical AD symptoms (Fig. 1).

\section{The Model System of Eyeblink Classical Conditioning}

Based on a foundation of behavioral neuroscience research initiated in nonhuman mammals, classical conditioning of the eyeblink response has become one of the best-documented learning paradigms in all mammals, including humans. There is extensive evidence that the neural circuitry for classical eyeblink conditioning is similar in humans and nonhuman mammals. With regard to normal aging, it was suggested that classical conditioning may be the Rosetta stone for brain substrates of age-related deficits in learning and memory [32].

Ivan Petrovich Pavlov elucidated the phenomenon of classical conditioning in dogs and first observed that old dogs conditioned more slowly than young dogs. Russian scientists were also the first to discover age-related impairment in human eyeblink classical conditioning (reported in [33]). This observation of large effects of age on eyeblink 


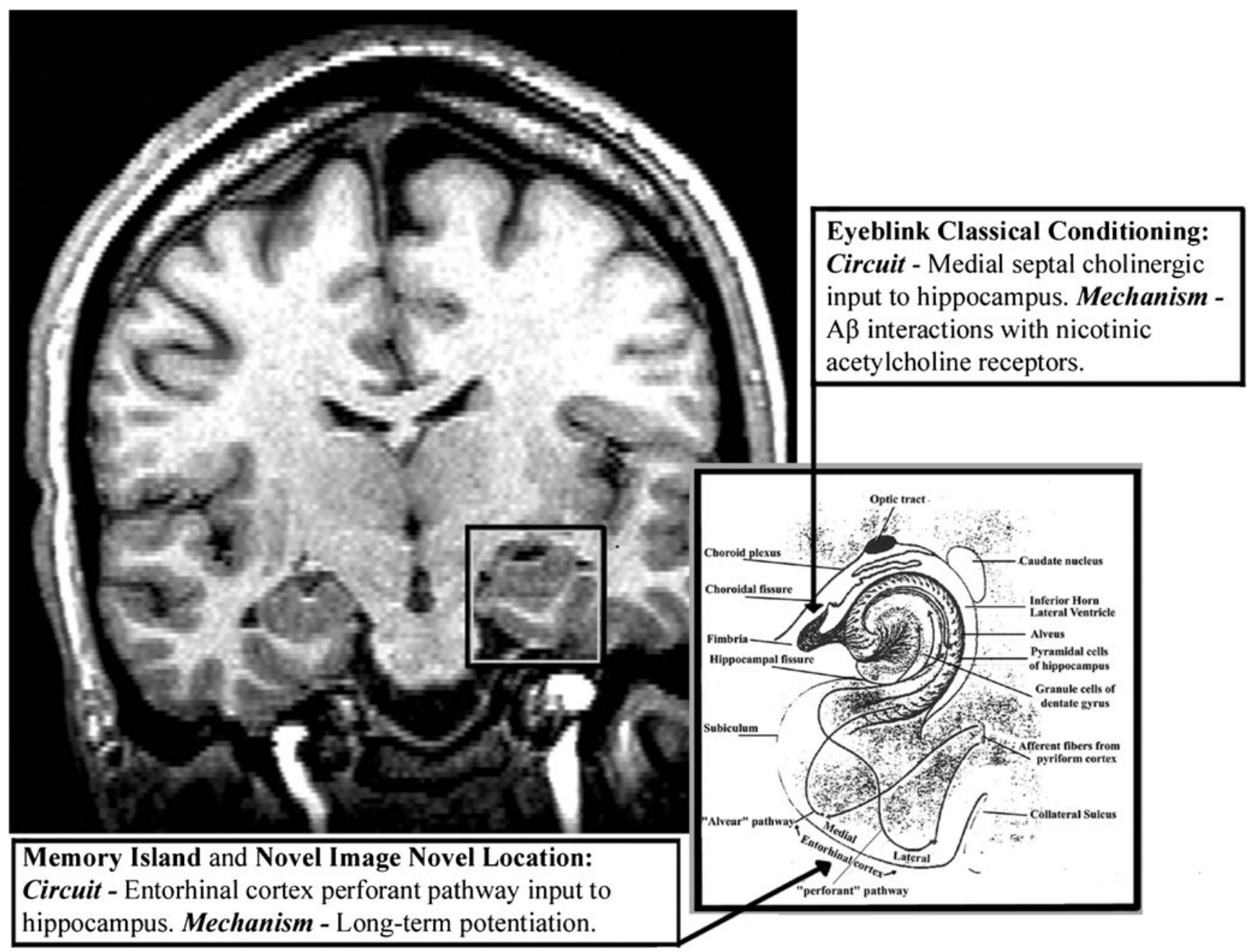

Fig. 1 Brain circuits affected in prodromal Alzheimer's disease (AD) that are engaged in three neuroscience-based tests. 3-Tesla coronal MRI of a healthy 33-year-old male is displayed on the left. The box on the MRI highlights the left medial temporal lobe including the hippocampus and associated structures. Illustration of medial temporal lobe structures highlighted in MRI is displayed on the right. Eyeblink classical conditioning engages medial septal cholinergic input into the

classical conditioning has been replicated and extended in many laboratories (reviewed in [34]).

\section{Eyeblink Classical Conditioning in Alzheimer's Disease}

In eyeblink classical conditioning, a neutral stimulus such as a sound (that would not normally elicit a blink) is presented for about half a second before an air puff directed at the cornea (that by itself does elicit a blink) occurs. The sound (usually a pure tone of $1 \mathrm{KHz}$ ) and mild (3-5 psi) air puff are presented together in this manner: the tone is on for about $400 \mathrm{~ms}$ before the air puff comes on for $100 \mathrm{~ms}$, and then they turn off together. With repeated presentations of the tone and air puff, called the conditioned and unconditioned stimulus (CS and US, respectively), the organism hippocampus carried in the fimbria. Nicotinic acetylcholine receptors in this circuit are impaired by $\mathrm{A} \beta$ oligomers and fibrils early on in the early prodromal phase of AD. Memory Island and Novel Image Novel Location engage entorhinal cortex input to hippocampus via the perforant pathway. Long-term potentiation is disrupted in this circuit by early AD pathology $\mathrm{A} \beta$ - Beta amyloid; MRI - magnetic resonance imaging

learns to blink to the tone before the air puff comes on. The learned blink that occurs before the air puff comes on is called the conditioned response (CR). Pavlov discovered that the neutral stimulus had to be on for a short while before the onset of the reflex-eliciting stimulus for learning to occur, and he called this timing of CS and US the "delay" classical conditioning paradigm.

Richard Thompson's group discovered that the hippocampus was activated in delay eyeblink classical conditioning in electrophysiological recording studies [35]. Human neuroimaging studies have found analogous hippocampal activation during eyeblink conditioning [36-38]. In the initial behavioral pharmacology studies, Moore et al. [39] reported that systemic administration of the muscarinic acetylcholine antagonist scopolamine disrupted acquisition, 
and this result also has been reported in human eyeblink conditioning [40, 41]. Interestingly, compared to wild-type mice, mice lacking apoE $\left(\right.$ Apoe $\left.^{--}\right)$had a reduced number of cortical and hippocampal muscarinic acetylcholine receptors. Whereas scopolamine had a small effect on delay eyeblink classical conditioning in wild-type mice, it had a large effect in $A p o e^{-/}$mice, supporting a role for apoE in cholinergic function [42•]. Impaired apoE functioning may exacerbate cholinergic deficits that contribute to the cognitive impairments seen in AD. While muscarinic acetylcholine receptor number remains stable in late-onset sporadic $\mathrm{AD}$ [16], some subtypes of nAChRs are lost [43-45].

The septohippocampal acetylcholine system is much involved in delay eyeblink classical conditioning. The medial septum is the locus of neurons that release acetylcholine throughout the hippocampus. Medial septal multiple unit activity is elicited during delay eyeblink conditioning [46], and lesions of the medial septum [47] or infusion of scopolamine into the medial septum $[18,48]$ impair delay eyeblink conditioning. Hasselmo [49] suggested that one role of septohippocampal projections is to modulate processing in the hippocampus and that high levels of acetylcholine in the septohippocampal pathway may increase the rate at which new information is processed. Consistent with this notion is the fact that hippocampal acetylcholine increased during delay eyeblink conditioning [50].

As mentioned previously, the cholinergic system loses some classes of receptors in AD. Audioradiographic and histochemical studies of postmortem human brain tissue (eg, Perry et al. [51]) and brain imaging studies in living AD patients [52] demonstrated specific loss of nAChRs in AD. More specifically, the $\alpha 4$ subunit-bearing subtype is selectively lost in $\mathrm{AD}$, whereas the $\alpha 7 \mathrm{nAChR}$ is retained [43-45]. An antagonist to nAChRs impairs acquisition of CRs [53], whereas agonists selective to nAChRs ameliorate eyeblink conditioning [54] and reverse antagonist effects [55]. Receptor binding studies demonstrated that poor conditioning is associated with lower numbers of nAChRs with the $\alpha 4$ subunit-bearing subtype [19, 20•].

The hippocampus is not the essential site for acquisition of CRs; the essential site is in the cerebellum. Disruption of the brain cholinergic system links AD to the model system of eyeblink conditioning in mammals, including humans [56]. Impairment resulting from septohippocampal cholinergic perturbations and impairment and loss of nAChRs are features of prodromal AD that may be detected by eyeblink classical conditioning.

We first demonstrated that 400-ms delay eyeblink classical conditioning was extremely disrupted in a sample of 20 individuals of a mean age of 82 years with moderate to severe $A D$ [57]. Normal older adults are impaired in eyeblink classical conditioning compared to young adults, but all age groups of normal, nondemented adults, including adults in their 80 s and
90 s, show clear evidence of associative learning. In probable $\mathrm{AD}$, there is very limited eyeblink conditioning in the first session of testing. However, when given a sufficient number of training trials (eg, 4 or 5 days of 90 -trial presentations), patients diagnosed with probable $\mathrm{AD}$ acquire CRs [58, 59]. This slowing of the rate of acquisition occurs in animal models when antagonists to cholinergic neurotransmission are introduced $[39,60]$. There is strong evidence that the site of interference of cholinergic antagonists in rabbits is the hippocampus $[61,62]$. Thus, the results that patients with $\mathrm{AD}$ are slow to acquire CRs but eventually do acquire CRs parallels results in rabbits with disruption of the hippocampal cholinergic system. The fact that probable AD patients eventually acquire CRs suggests that the essential cerebellar circuitry for $\mathrm{CR}$ acquisition is intact, but that acquisition is disrupted in medial temporal lobe structures. These results parallel knowledge about human $\mathrm{AD}$ neuropathology: the cerebellum remains relatively intact.

Eyeblink conditioning had a sensitivity of $95 \%$ for $\mathrm{AD}$ in our initial study [57]. Solomon et al. [63] reported disruption of eyeblink conditioning in the 400-ms delay paradigm in a sample of probable AD patients in the early $70 \mathrm{~s}$, a decade younger than our first sample. An additional replication in which eyeblink conditioning was shown to differentiate some cerebrovascular dementia patients from patients with probable AD was performed [64]. Sensitivity for $\mathrm{AD}$ in that sample was $86 \%$, and it was $100 \%$ in a sample of patients diagnosed with $\mathrm{AD}$ at an $\mathrm{AD}$ research center [65]. Eyeblink conditioning in adults with Down's syndrome and $\mathrm{AD}$ neuropathology over the age of 35 years was similar to conditioning in probable AD patients [66, 67]. Furthermore, eyeblink conditioning is selective to $\mathrm{AD}$ neuropathology. Eyeblink classical conditioning in patients with other neurodegenerative diseases such as Huntington's disease [68] and Parkinson's disease [69, 70] is relatively normal and clearly differentiated from eyeblink conditioning in $\mathrm{AD}$.

\section{Eyeblink Classical Conditioning and Early Detection of Alzheimer's Disease}

Longitudinal results suggest that eyeblink conditioning has utility in early detection. Of the 20 age-matched control patients in the initial testing, 8 showed conditioning in the AD range [57]. Of the eight poor conditioning control patients, four developed dementia within 3 years and one died [71]. Thus, of eight nondemented patients age-matched to probable $\mathrm{AD}$ patients who scored on eyeblink conditioning in the $\mathrm{AD}$ range, only three remained cognitively normal. The 12 age-matched control patients scoring in the normal range remained cognitively intact. This 3-year longitudinal study of nondemented adults tested on eyeblink conditioning revealed that $63 \%$ of the cognitively 
normal patients who were poor conditioners developed dementia within 3 years.

A second longitudinal study followed 20 cognitively normal elderly participants over a 2-year period (half good conditioners, half poor conditioners) [72]. A neuropsychological test battery administered 2 years after the initial eyeblink conditioning revealed significantly worse performance in poor conditioners on visuospatial abilities, semantic memory, and language, abilities showing early decline in AD. Over a 2-year period, two of the poor conditioners (and none of the good conditioners) failed significantly, and one was diagnosed with probable AD.

Results from a third follow-up study of older adults tested 5 to 8 years previously also indicated that poor-conditioning older adults scored significantly lower on neuropsychological tests used to characterize cognitive deficits in $\mathrm{AD} \mathrm{[65].}$ Among 59 patients over the age of 70 years, eyeblink conditioning scores less than $25 \%$ CRs were associated with significantly poorer performance on clock-drawing tests. All neuropsychological test scores were numerically lower in poor conditioners. These results suggest that poor performance on $400-\mathrm{ms}$ delay eyeblink classical conditioning predicts subsequent cognitive impairment at a point in time when older adults are still cognitively intact.

\section{0-ms Delay: Optimal Paradigm for Early Detection}

Given that eyeblink conditioning may have utility in the early detection of $\mathrm{AD}$, we sought to identify the eyeblink conditioning paradigm that would maximize early detection. We explored performance on the 750-ms trace paradigm with a $250-\mathrm{ms}$ CS and a $500-\mathrm{ms}$ trace period [73]. The 750-ms trace procedure did not improve AD detection. Whereas the 400-ms delay procedure had a sensitivity for $\mathrm{AD}$ of $95 \%$ [51], the 750-ms trace procedure had a sensitivity for $\mathrm{AD}$ of 54\% [73]. Among the reasons that we suspected that the $750-\mathrm{ms}$ trace eyeblink conditioning paradigm may have advantages for differentiating nondemented elderly patients from $\mathrm{AD}$ patients was that, in nonhuman animals, the hippocampus is essential in the trace procedure when the trace interval exceeds $300 \mathrm{~ms}$ [74]. More recently, it was demonstrated that in humans, the trace interval must be extended to $1000 \mathrm{~ms}$ for the hippocampus to be essential in trace eyeblink conditioning [75]. We have chosen not to explore a $1000-\mathrm{ms}$ trace procedure in patients diagnosed with probable $\mathrm{AD}$ because of the difficulty of scoring CRs in long intervals that are within the spontaneous blink rate of humans.

Another feature of an optimal screening test is that it is relatively short. Many of our human eyeblink conditioning studies have used 90 trials and taken at least $45 \mathrm{~min}$ to complete. We correlated 10 to 80 total trials with the full 90-trial session in 240 patients and found that a session of 60 trials correlates 0.96 with 90 trials [76]. A 60-trial session lasts about $25 \mathrm{~min}$. The data also indicated that performance variability increased in the last third of a 90-trial session, probably due to fatigue and/or boredom. A 25-min session provides a reliable assessment of eyeblink conditioning performance.

Because eyeblink conditioning is simple, nonthreatening, and noninvasive, it may be a useful addition to test batteries designed to detect $\mathrm{AD}$ in the prodromal phase. There are practical advantages to eyeblink conditioning as an assessment tool. With this test, the patients are not aware of the response that is being measured. They are able to watch an entertaining video throughout the test, making it a relaxing and enjoyable experience.

\section{A Human Virtual Reality Version of the Morris Water Maze: Memory Island}

Another neuroscience-based test that is enjoyable for participants is Memory Island, a spatial learning and memory task that is being assessed in a virtual reality environment [77]. Memory Island is based on the extensive use of water maze tests to assess mechanisms of spatial learning and memory in rodents. As a test of spatial ability, the water maze requires the rodent to navigate to the location of an escape platform that is hidden under water. This test was originally developed to examine the contribution of the hippocampus to navigation and place learning in the rat [78]. Subsequent research has confirmed the essential role of the hippocampus in this task and extended it from rats to mice. The water maze is one of the most widely used behavioral tests in studies of normal aging in rodents [79•]. It has been used extensively in studies of transgenic mouse models of $\mathrm{AD}$ and is thought to parallel the impaired spatial ability seen in human patients with AD. Spatial ability becomes affected in prodromal $\mathrm{AD}$. In this condition, $\mathrm{A} \beta$ begins to disrupt perforant pathway input to hippocampus from the entorhinal cortex. Mechanisms of spatial learning associated with the water maze task include long-term potentiation (LTP) in the entorhinal cortex perforant pathway-hippocampus circuit. The first demonstration of synaptic potentiation in the hippocampus during learning about the environment was performed in Per Anderson's laboratory [80]. Synaptic field potentials were recorded in the dentate gyrus in response to stimulation of the perforant path in rats exploring a novel environment. Both the field excitatory postsynaptic potential and the population spike increased significantly early in the exploration in a time course similar to that of short-term potentiation. Subsequently, members of this group demonstrated an association between LTP in the perforant pathway input to hippocampus from entorhinal cortex and spatial 
learning in the water maze $[81,82]$. Furthermore, synthetic $\mathrm{A} \beta$ peptides inhibited LTP induction significantly in rat hippocampal slices without affecting the basal synaptic transmission and posttetanic potentiation in the dentate medial perforant path [83]. Such an effect may impair spatial learning in prodromal $\mathrm{AD}$ before actual loss of synapses and neurons has occurred.

The human virtual reality environment for the human task is an island comprising four quadrants, each containing a different target object (sculpture, seagull, seal, or fountain). Targets in all four quadrants are used for visible target training in distinct trials. The starting orientation of the participant is varied in each trial, but these variations are kept consistent across participants. These different orientations are intended to prevent using response strategies like always heading in one direction across trials. Participants practice this task using a joystick to a target location visibly marked with a flag adjacent to the target. After completing the visible target training, they navigate to a hidden target (ie, no flag located beside the target item). In this part of the test, the study participant has to remember where the hidden target is and how to get there. The location of the hidden target is kept constant for all participants. In each trial of the visible or hidden session, if the study participant is unable to locate the target within $2 \mathrm{~min}$, a directional arrow appears to guide the participant to the target. after the last hidden target trial, the participant receives a 30 -s probe trial with the target removed. In each trial, navigation is recorded in timestamped coordinate files, which are used to calculate distance traveled (virtual units), cumulative distance to the target (virtual units), latency to reach the target (seconds), and speed (virtual units/sec). The primary outcome measures during the probe trial are the percent of time spent in each quadrant and the cumulative distance to the target.

Adults in the age range of 40 to 67 years perform worse on Memory Island in comparison to adolescents and young adults [84]. Previously, it had been shown that there was an effect of $A P O E \& 4$ on test performance among 116 nondemented older adults (mean age: 81 years) assessed on established tests of memory and on Memory Island and Novel Image Novel Location, with non- $A P O E \& 4$ carriers outperforming $A P O E \varepsilon 4$ carriers, but not in other cognitive tests [85].

In the Novel Image Novel Location test, a set of 12 panels, each containing three images in three of the four quadrants (one quadrant was empty), is presented to the participants to memorize. After no delay (immediate), participants are presented with a second set of panels that are either the same (no change), contain one novel image (novel image), or contain an image moved to the empty quadrant (novel location). Then after a delay $(5 \mathrm{~min})$ the participants are presented with a third set of panels that are either the same (no change), contain one novel image (novel image), or contain an image moved to the empty quadrant (novel location). The sequence of the panels is different in the second and third sets. The participants are asked to correctly identify if there was a change and, if so, how the panel changed (novel image/novel location) and what was the location of the change (quadrant). Memory Island and Novel Image Novel Location are especially sensitive to memory impairment in $A P O E \varepsilon 4$ carriers and, thus, sensitive to prodromal $\mathrm{AD}$.

\section{Comparing Memory Island to Traditional Spatial Tests of Human Cognition}

Typically, human spatial ability is assessed with tests such as the Spatial Span Forward and Backward that use blocks attached to a tray [86]. The experimenter points to a series of blocks and asks the participant to repeat the order in which the blocks have been identified. Such a task is substantially different from spatial navigation in rodents as required by the water maze. The rodent navigation tasks are administered with an allocentric (or environment-centered) frame of reference in which the animal is required to use navigation to orient within a large space. Spatial Span and other human neuropsychological tests of spatial ability do not involve navigation. In traditional tests, all the information for the task is held within a single visual field or frame of reference, providing an egocentric (or self-centered) frame of reference. Banta Lavenex et al. [87] assessed human patients' reliance on sources of spatial information by testing four different conditions, controlling for participants' reliance on egocentric and/or allocentric frames of reference. Results demonstrated that changes in viewpoint produced by the movement of images placed in front of a stationary patient was not equivalent to the movement of the patient around stationary images. Studies using functional MRI (fMRI) demonstrate that egocentric and allocentric frames of reference engage different brain substrates of learning [88•]. Thus, traditional neuropsychological tests of spatial learning and memory in humans do not have the translational power that can be derived from building knowledge on animal models in which mechanisms of learning and memory have been elaborated at cellular and molecular levels.

Advances in technology have enabled the development of human tests of spatial navigation with the use of computerized virtual reality. The virtual testing environment of Memory Island simulates the water maze environment that rodents experience and requires navigation to a hidden location just as in the rodent water maze task. Virtual reality thus can help to bridge the gap between electrophysiological studies in rodents and brain imaging studies using fMRI in humans [89]. Using fMRI, Folley et al. [90] reported that temporal and frontal lobe regions were recruited by the hidden platform condition of a virtual water maze task, with 
coupling between neural circuits, regional neuroanatomy, and behavior. The hippocampus and parahippocampal cortices exhibit theta oscillations during spatial navigation in rodents that are thought to mediate spatial memory formation. Neuromagnetic activity was recorded with a wholehead 275-channel magnetoencephalographic system as healthy participants navigated to a hidden platform in a virtual reality Morris water maze [91]. Analysis revealed greater theta activity in the left anterior hippocampus and parahippocampal cortices during goal-directed navigation relative to aimless movements in a sensorimotor control condition. Additional analyses showed that left anterior hippocampal activity was predominantly observed during the first half of training, pointing to a role for this region in early learning.

\section{Object Recognition with a Spatial Component: Novel Image Novel Location}

Neuroscience-based assessment of spatial learning and memory in animal models is also evaluated using object recognition tests containing a spatial component. Including the spatial component increases sensitivity compared to more traditional object recognition tasks and also provides direct application to early detection of AD. As emphasized previously, reduction in axons and synapses in the perforant pathway input into hippocampus from the entorhinal cortex is one of the earliest of the neural and synaptic changes in $\mathrm{AD}$ [22] and is associated with early $\mathrm{A} \beta$ accumulation. Following up 6 to 18 months later on the nondemented older adults assessed by Bertreau-Pavy et al. [85] on established tests of memory and on translational tests of spatial cognition, Haley et al. [92] assessed effects of APOE \&4 on study "dropouts" (participants that did not return for the second and/or third session[s]) and "finishers" (participants that returned for all sessions). There were effects of $A P O E$ $\varepsilon 4$ on dropout rates and Novel Image Novel Location total scores as well as subscores in both dropouts and finishers. Novel Image Novel Location total score was a predictor of $A P O E \& 4$ participant dropout. Compared to non-APOE $\varepsilon 4$ dropouts, $A P O E \varepsilon 4$ dropouts had lower Novel Image Novel Location scores. In contrast, $A P O E \& 4$ finishers had higher Novel Image Novel Location scores than non$A P O E$ \& 4 finishers. A 4-year follow-up of performance on the Mini-Mental State Examination (MMSE) [93] and the Novel Image Novel Location tests indicated that whereas MMSE scores did not change over the 4-year period, Novel Image Novel Location scores did change in some older adults [94•]. Novel Image Novel Location scores correlated with logical memory and word recall lists, cognitive tasks used to detect dementia in the clinic, as well as clinical dementia rating scales. Recent validation results from Steven Ferris' laboratory relating biomarker data in cognitively normal elderly participants to a task similar to Novel Image Novel Location demonstrated task sensitivity to higher levels of CSF A $\beta$ and hippocampal atrophy [95].

\section{Conclusions}

There is an increasing need for assessment of cognition in early dementia [96*•]. Based on animal models of neurological conditions, we developed sensitive neuroscience-based cognitive tests to detect early cognitive changes in prodromal $\mathrm{AD}$ in humans that are prime candidates. Therefore, increased efforts are warranted to use such translational cognitive assessments detecting synaptic changes as part of early diagnostic and subsequently intervention studies. As Dennis Selkoe [97] recently wrote, "Rigorous preclinical validation of mechanism-based therapeutic agents followed by meticulously designed trials that focus on the cardinal cognitive symptoms [emphasis is ours] and their associated biomarkers in the mild or presymptomatic phases of Alzheimer's disease are likely to lead to success, perhaps in the not-too-distant future" (p. 1060).

Acknowledgements We thank Reid Olsen for assistance with the figure preparation.

This work was supported by grants from the National Institute on Aging (NIA [5 R01 AG09752, AG021925, AG023742]), the Alzheimer's Association, and Stern Family Foundation to Dr. Diana Woodruff-Pak, and from the Ellison Medical Foundation (EMF AGNS-0201), the Medical Research Foundation of Oregon, a Pilot Project of the Layton Center for Aging and Alzheimer's Disease, and AG20904 to Dr. Jacob Raber, as well as Public Health Service Grant 5 M01 RR000334 and Alzheimer's Disease Center NIA Grant P30 AG08017.

The Oregon Health \& Science University technology transfer office might request a modest one-time licensing fee from laboratories that request the Novel Image Novel Location and Memory Island programs.

Disclosures No potential conflicts of interest relevant to this article were reported.

\section{References}

Paper of particular interest, published recently, have been highlighted as:

- of importance

•- of major importance

1. McKhann G, Drachman D, Folstein M, et al. Clinical diagnosis of Alzheimer's disease: report of the NINCDS-ADRDA Work Group under the auspices of Department of Health and Human Services Task Force on Alzheimer's Disease. Neurology. 1984;34:939-44.

2. McKhann G, Knopman DS, Chertkow H, et al. The diagnosis of dementia due the Alzheimer's disease: Recommendations from the National Institute on Aging-Alzheimer's Association workgroups 
on diagnostic guidelines for Alzheimer's disease. Alzheimers Dement. 2011;7:263-9.

3. Hyman BT. The neuropathological diagnosis of Alzheimer's disease: clinical-pathological studies. Neurobiol Aging. 1997;18(4 Suppl):S27-32.

4. Dubois B, Feldman HH, Jacova C, et al. Research criteria for the diagnosis of Alzheimer's disease: revising the NINCDS-ADRDA criteria. Lancet Neurol. 2007;6:734-46.

5. •• Dubois B, Feldman HH, Jacova C, et al.: Revising the diagnosis of Alzheimer's disease: a new lexicon. Lancet Neurol 2010, 9:1118-1111. This is a consensus statement by an international group of authorities initiated by European scientist-clinicians on the long prodromal phase of Alzheimer's disease that exists before it is diagnosed clinically.

6. - Sperling RA, Aisen PS, Beckett LA, et al.: Toward defining the preclinical stages of Alzheimer's disease: recommendations from the National Institute on Aging-Alzheimer's Association workgroups on diagnostic guidelines for Alzheimer's disease. Alzheimers Dement 2011, 7:280-292. Recognition of developments in Alzheimer's disease research and treatment led leaders in the National Institute on Aging and Alzheimer's Association to convene a panel of experts to make a statement about the preclinical or prodromal phase of Alzheimer's disease. This is a conceptual statement emphasizing the need for more research to define parameters and understand mechanisms of early disease development and to underscore the urgent need to treat individuals before irreversible loss of brain tissue.

7. • Villemange VL, Pike KE, Chetelat G, et al.: Longitudinal assessment of $\mathrm{A} \beta$ and cognition in aging and Alzheimer disease. Ann Neurol 2011, 69:181-192. The authors follow-up as many as 3 years of over 200 patients, assessing PiB-PET that demonstrated slow increases in $A \beta$ deposition from cognitive normality to moderately severe dementia. Cognitive decline was only weakly related to change in A $\beta$ burden, suggesting that additional factors have a more direct effect on symptom progression.

8. •- Karran E, Mercken M, De Strooper B: The amyloid cascade hypothesis for Alzheimer's disease: an appraisal for the development of therapeutics. Nat Rev Drug Discov 2011, 10:698-712. This is an outstanding review of the amyloid cascade hypothesis, suggesting that changes in the amount of A $\beta$ trigger downstream processes may cause neuronal loss, paired helical filaments of tau, and clinically detected cognitive symptoms of dementia.

9. Roses AD. Apolipoprotein E affects the rate of Alzheimer disease expression: beta-amyloid burden is a secondary consequence dependent on APOE genotype and duration of disease. J Neuropathol Exp Neurol. 1994;53:429-37.

10. • Castellano JM, Kim J, Stewart FR, et al.: Human apoE isoforms differentially regulate brain amyloid- $\beta$ peptide clearance. Sci Transl Med 2011, 3:89ra57. Compelling evidence to demonstrate mechanisms by which apoE isoforms impair the clearance of brain $A \beta$ is amassed in this article.

11. Caselli RJ, Dueck AC, Osborne D, et al. Longitudinal modeling of age-related memory decline and the APOE epsilon4 effect. N Engl J Med. 2009;361:255-63.

12. Bartus RT, Dean 3rd RL, Beer B, et al. The cholinergic hypothesis of geriatric memory dysfunction. Science. 1982;217:408-14.

13. Davies P, Maloney AJ. Selective loss of central cholinergic neurons in Alzheimer's disease. Lancet. 1976;2:1403.

14. Perry EK, Tomlinson BE, Blessed G, et al. Correlation of cholinergic abnormalities with senile plaques and mental test scores in senile dementia. Br Med J. 1978;2:1457-9.

15. DeKosky ST, Ikonomovic MD, Styren SD, et al. Upregulation of choline acetyltransferase activity in hippocampus and frontal cortex of elderly subjects with mild cognitive impairment. Ann Neurol. 2002;51:145-55.

16. Mufson EJ, Ginsberg SD, Ikonomovic MD, et al. Human cholinergic basal forebrain: chemoanatomy and neurologic dysfunction. J Chem Neuroanat. 2003;26:233-42.
17. - Bao F, Wicklund L, Lacor PN, et al.: Different $\beta$-amyloid oligomer assemblies in Alzheimer brains correlate with age of disease onset and impaired cholinergic activity. Neurobiol Aging 2011 Jun 15. [Epub ahead of print]. This article demonstrates a causal relationship between distinct $A \beta$ oligomers and impairment of acetylcholine neurotransmission.

18. Solomon PR, Gottfried KE. The septohippocampal cholinergic system and classical conditioning of the rabbit's nictitating membrane response. J Comp Physiol Psychol. 1981;95:322-30.

19. Li J-G, Lehr MA, Liu-Chen L-Y, et al. Nicotinic acetylcholine receptors and modulation of learning in 4- and 27-month-old rabbits. Neuropsychopharmacol. 2008;33:2820-30.

20. • Woodruff-Pak DS, Lehr MA, Li J-G, et al.: Good learners have higher levels of brain nicotinic receptor binding than poor learners. Neurobiol Aging 2010, 31:1032-1043. Data presented in this article demonstrate an association between nicotinic acetylcholine receptors and proficiency in eyeblink classical conditioning.

21. Brown KL, Comalli DM, De Biasi M, et al. Trace eyeblink conditioning is impaired in $\alpha 7$ but not in $\beta 2$ nicotinic acetylcholine receptor knock-out mice. Front Behav Neurosci. 2010;4:166.

22. Gomez-Isla T, Price JL, McKeel DW, et al. Profound loss of layer II entorhinal cortex neurons occurs in very mild Alzheimer's disease. J Neurosci. 1996;16:4491-500.

23. Mizutani T, Kashara M. Degeneration of the intrahippocampal routes of the perforant and alvear pathways in senile dementia of Alzheimer type. Neurosci Lett. 1995;184:141-4.

24. Stoub TR, deToledo-Morrell L, Stebbins GT, et al. Hippocampal disconnection contributes to memory dysfunction in individuals at risk for Alzheimer's disease. Proc Natl Acad Sci U S A. 2006;103:10041-5.

25. deToledo-Morrell L, Stoub TR, Wang C. Hippocampal atrophy and disconnection in incipient and mild Alzheimer's disease. Prog Brain Res. 2007;163:741-53.

26. Chetelat G, Villemagne VL, Pike KE, et al. Independent contribution of temporal beta-amyloid deposition to memory decline in the pre-dementia phase of Alzheimer's disease. Brain. 2011;134:798807.

27. Herholz K, Ebmeier K. Clinical amyloid imaging in Alzheimer's disease. Lancet Neurol. 2011;10:667-70.

28. Sojkova J, Zhou Y, An Y, et al. Longitudinal patterns of $\beta$-amyloid deposition in nondemented older adults. Arch Neurol. 2011;68:644-9.

29. Harris JA, Devidze N, Verret L, et al. Transsynaptic progression of amyloid- $\beta$-induced neuronal dysfunction within the entorhinalhippocampal network. Neuron. 2010;68:428-41.

30. Reilly JF, Games D, Rydel RE, et al. Amyloid deposition in the hippocampus and entorhinal cortex: quantitative analysis of a transgenic mouse model. Proc Natl Acad Sci U S A. 2003;100:4837-42.

31. Su Y, Ni B. Selective deposition of amyloid-beta protein in the entorhinal-dentate projection of a transgenic mouse model of Alzheimer's disease. J Neurosci Res. 1998;53:177-86.

32. Thompson RF. Classical conditioning: The Rosetta stone for brain substrates of age-related deficits in learning and memory? Neurobiol Aging. 1988;9:547-8.

33. Jerome EA. Age and learning - experimental studies. In: Birren JE, editor. Handbook of Aging and the Individual. Chicago: University of Chicago Press; 1959. p. 655-99.

34. Green JT, Woodruff-Pak DS. Eyeblink classical conditioning in aging animals. In: Woodruff-Pak DS, Steinmetz JE, editors. Eyeblink Classical Conditioning: Volume II, Animal Models. Boston: Kluwer; 2000. p. 155-78.

35. Berger TW, Alger BE, Thompson RF. Neuronal substrate of classical conditioning in the hippocampus. Science. 1976;192:483-5.

36. Blaxton TA, Zeffiro TA, Gabrieli JDE, et al. Functional mapping of human learning: a positron-emission tomography study of eyeblink conditioning. J Neurosci. 1996;16:4032-40. 
37. Logan CG, Grafton ST. Functional anatomy of human eyeblink conditioning determined with regional cerebral glucose metabolism and positron emission tomography. Proc Nat Acad Sci USA. 1995;92:7500-4.

38. Lemieux SK, Woodruff-Pak DS. Functional magnetic resonance imaging studies of eyeblink classical conditioning In Eyeblink Classical Conditioning: Volume I, Applications in Humans. Boston: Kluwer; 2000. p. 71-93.

39. Moore JW, Goodell NA, Solomon PR. Central cholinergic blockade by scopolamine and habituation, classical conditioning, and latent inhibition of the rabbit's nictitating membrane response. Physiol Psychol. 1976;4:395-9.

40. Bahro M, Schreurs BG, Sunderland T, et al. The effects of scopolamine, lorazepam, and glycopyrrolate on classical conditioning of the human eyeblink response. Psychopharmacol. 1995;122:395400 .

41. Solomon PR, Groccia-Ellison M, Flynn D, et al. Disruption of human eyeblink conditioning after central cholinergic blockade with scopolamine. Behav Neurosci. 1993;107:271-9.

42. - Siegel JA, Benice TS, van Meer P, et al.: Acetylcholine receptor and behavioral deficits in mice lacking apolipoprotein E. Neurobiol Aging 2011, 32:75-84. Data presented in this paper indicate that impaired apoE functioning may result in cholinergic deficits that contribute to cognitive impairment in Alzheimer's disease.

43. Martin-Ruiz CM, Court JA, Molnar E, et al. Alpha4 but not alpha3 and alpha7 nicotinic acetylcholine receptor subunits are lost from the temporal cortex in Alzheimer's disease. J Neurochem. 1999;73:1635-40.

44. Warpman U, Nordberg A. Epibatidine and ABT 418 reveal selective losses of $\alpha 4 \beta 2$ nicotinic receptors in Alzheimer brains. NeuroReport. 1999;6:2419-23.

45. Wevers A, Monteggia L, Lowack S, et al. Expression of nicotinic acetylcholine receptor subunits in the cerebral cortex in Alzheimer's disease: histotopographical correlation with amyloid plaques and hyperphosphorylated-tau protein. Eur J Neurosci. 1999;11:25515.

46. Berger TW, Clark GA, Thompson RF. Neuronal plasticity recorded from limbic structures during conditioning. Physiol Psychol. 1980;8:157-67.

47. Berry SD, Thompson RF. Medial-septal lesions retard classical conditioning of the rabbit nictitating membrane response in rabbits. Science. 1979;205:209-11.

48. Powell DA, Hernandez L, Buchanan SL. Intraseptal scopolamine has differential effects on Pavlovian eye blink and heart rate conditioning. Behav Neurosci. 1985;99:75-87.

49. Hasselmo M. Neuromodulation and cortical function: Modeling the physiological basis of behavior. Behav Brain Res. 1995;67:127.

50. Meyer JJ, Allen DD, Yokel RA. Hippocampal acetylcholine increases during eyeblink conditioning in the rabbit. Physiol Behav. 1996;60:1199-2003.

51. Perry EK, Morris C, Court $\mathrm{J}$, et al. Alteration in nicotine binding sites in Parkinson's disease, Lewy body dementia and Alzheimer's disease: Possible index of early neuropathology. Neurosci. 1995;64:385-95.

52. Nordberg A, Lundqvist A, Hartvig P, et al. Kinetic analysis of regional $11 \mathrm{C}$-nicotine binding in normal and Alzheimer brains: in vivo assessment using positron emission tomography. Alzheimer Dis Assoc Disord. 1995;9:21-7.

53. Woodruff-Pak DS, Li Y-T, Kazmi A, et al. Nicotinic cholinergic system involvement in eyeblink classical conditioning in rabbits. Behav Neurosci. 1994;108:486-93.

54. Woodruff-Pak DS, Li Y-T, Kem WR. A nicotinic agonist (GTS21), eyeblink classical conditioning, and nicotinic receptor binding in rabbit brain. Brain Res. 1994;645:309-17.
55. Woodruff-Pak DS, Vogel III RW. Wenk GL: Mecamylamine interactions with galantamine and donepezil: effects on learning, acetylcholinesterase, and nicotinic acetylcholine receptors. Neurosci. 2003;117:439-47.

56. Woodruff-Pak DS, Finkbiner RG, Katz IR. A model system demonstrating parallels in animal and human aging: extension to Alzheimer's disease. In: Meyer EM, Simpkins JW, Yamamoto J, editors. Novel approaches to the treatment of Alzheimer's disease. New York: Plenum; 1989. p. 355-71.

57. Woodruff-Pak DS, Finkbiner RG, Sasse DK. Eyeblink conditioning discriminates Alzheimer's patients from non-demented aged. NeuroReport. 1990;1:45-8.

58. Solomon PR, Brett M, Groccia-Ellison M, et al. Classical conditioning in patients with Alzheimer's disease: a multiday study. Psychol Aging. 1995; 10:248-54.

59. Woodruff-Pak DS, Romano S, Papka M. Training to criterion in eyeblink classical conditioning in Alzheimer's disease, Down's syndrome with Alzheimer's disease, and healthy elderly. Behav Neurosci. 1996;110:22-9.

60. Woodruff-Pak DS, Hinchliffe RM. Mecamylamine- or scopolamineinduced learning impairment: ameliorated by nefiracetam. Psychopharmacol. 1997;131:130-9.

61. Solomon PR, Solomon SD, Vander Schaaf E, et al. Altered activity in the hippocampus is more detrimental to classical conditioning than removing the structure. Science. 1983;220:329-31.

62. Woodruff-Pak DS, Li Y-T, Hinchliffe RM, et al. Hippocampus in delay eyeblink classical conditioning: essential for nefiracetam amelioration of leaning in older rabbits. Brain Res. 1997;747:207-18.

63. Solomon PR, Levine E, Bein T, et al. Disruption of classical conditioning in patients with Alzheimer's disease. Neurobiol Aging. 1991;12:283-7.

64. Woodruff-Pak DS, Papka M, Romano S, et al. Eyeblink classical conditioning in Alzheimer's disease and cerebrovascular dementia. Neurobiol Aging. 1996;17:505-12.

65. Woodruff-Pak DS. Eyeblink classical conditioning differentiates normal aging from Alzheimer's disease. Int Physiol Behav Sci. 2001;36:87-108.

66. Woodruff-Pak DS, Papka M, Simon EW. Eyeblink classical conditioning in Down's Syndrome, Fragile X Syndrome, and normal adults over and under age 35. Neuropsychol. 1994;8:14-24.

67. Papka M, Simon EW, Woodruff-Pak DS. A one-year longitudinal investigation of eyeblink classical conditioning and cognitive and behavioral tests in adults with Down's syndrome. Aging and Cognition. 1994;1:89-104.

68. Woodruff-Pak DS, Papka M. Huntington's disease and eyeblink classical conditioning: Normal learning but abnormal timing. J Internat Neuropsychol Soc. 1996;2:323-34.

69. Daum I, Schugens MM, Breitenstein C, et al. Classical eyeblink conditioning in Parkinson's disease. Movement Disord. 1996;11:639-46.

70. Sommer M, Grafman J, Clark K, et al. Learning in Parkinson's disease: eyeblink conditioning, declarative learning, and procedural learning. J Neurol Neurosurg Psychiatry. 1999;67:27-34.

71. Ferrante LS, Woodruff-Pak DS. Longitudinal investigation of eyeblink classical conditioning in the old-old. J Gerontol: Psychol Sci. 1995;50B:P42-50.

72. Downey-Lamb MM, Woodruff-Pak DS. Early detection of cognitive deficits using eyeblink classical conditioning. Alzheimer's Rep. 1999;2:37-44.

73. Woodruff-Pak DS, Papka M. Alzheimer's disease and eyeblink conditioning: $750 \mathrm{~ms}$ trace versus $400 \mathrm{~ms}$ delay paradigm. Neurobiol Aging. 1996;17:397-404.

74. Moyer JR, Deyo RA, Disterhoft JF. Hippocampectomy disrupts trace eye-blink conditioning in rabbits. Behav Neurosci. 1990;104:24352.

75. Clark RE, Squire LR. Classical conditioning and brain systems: the role of awareness. Science. 1998;280:77-81. 
76. Papka M, Woodruff-Pak DS. Number of trials needed to assess human eyeblink classical conditioning. Psychol Aging. 1996;11:373-6.

77. Haley GE, Raber J. Spatial learning and memory in animal models and humans. In: Raber J, editor. Animal Models of Behavioral Analysis. New York: Humana Press; 2011. p. 91-109.

78. Morris R. Developments of a water-maze procedure for studying spatial learning in the rat. J Neurosci Methods. 1984;11:47-60.

79. - Kennard JA, Woodruff-Pak DS: Age sensitivity of behavioral tests and brain substrates of normal aging in mice. Front Aging Neurosci 2011, 3:9. This article presents comparisons and contrasts of the sensitivity of neuroscience-based tests for cognitive assessment of normal aging in mouse models.

80. Moser E, Moser MB, Andersen P. Synaptic potentiation in the rat dentate gyrus during exploratory learning. Neuroreport. 1993;5:317-20.

81. Moser EI, Krobert KA, Moser MB, et al. Impaired spatial learning after saturation of long-term potentiation. Science. 1998;281:2038-42.

82. Brun VH, Ytterbo K, Morris RG, et al. Retrograde amnesia for spatial memory induced by NMDA receptor-mediated long-term potentiation. J Neurosci. 2001;21:356-62.

83. Chen QS, Kagan BL, Hirakura Y, et al. Impairment of hippocampal long-term potentiation by Alzheimer amyloid beta-peptides. J Neurosci Res. 2000;60:65-72.

84. Piper BJ, Acevedo SA, Edwards KR, et al. Age, sex, and handedness differentially contribute to neurospatial function on the Memory Island and Novel-Image Novel-Location tests. Physiol Behav. 2011;103:513-22.

85. Bertreau-Pavy F, Park B, Raber J. Effects of sex and APOE epsilon 4 on object recognition and spatial navigation in the elderly. Neurosci. 2007;147:6-17.

86. Wechsler D: WMS-III Administration and Scoring Manual. San Antonio, TX: Psychological Corporation.

87. Banta Lavenex P, Lecci S, Pretre V, et al. As the world turns: shortterm human spatial memory in egocentric and allocentric coordinates. Behav Brain Res. 2011;219:132-41.

88. - Manelis A, Reder LM, Hanson SJ: Dynamic changes in the medial temporal lobe during incidental learning of objectlocation associations. Cereb Cortex 2011, [Epub ahead of print] Event-related fMRI data were collected in human participants performing a visual search task to investigate the contributions of various medial temporal lobe subregions as learning occurred and task performance improved.

89. Doeller CF, Barry C, Burgess N: From cells to systems: grids and boundaries in spatial memory. Neuroscientist 2011 [Epub ahead of print]
90. Folley BS, Astur R, Jagannathan K, et al. Anomalous neural circuit function in schizophrenia during a virtual Morris water task. Neuroimage. 2010;49:3373-84.

91. Cornwell BR, Johnson LL, Holroyd T, et al. Human hippocampal and parahippocampal theta during goal-directed spatial navigation predicts performance on a virtual Morris water maze. J Neurosci. 2008;28:5983-90.

92. Haley GE, Berteau-Pavy F, Parkv B, et al. Effects of epsilon $\varepsilon 4$ on object recognition in the non-demented elderly. Curr Aging Sci. 2010;3:127-37.

93. Folstein MF, Robbins LN, Helzer JE. The Mini-Mental State Examination. Arch Gen Psychiat. 1983;40:812.

94. • Haley GE, Berteau-Pavy F, Berteau-Pavy D, et al.: Novel imagenovel location object recognition task sensitive to age-related cognitive decline in nondemented elderly. Age (Dordr) 2011, [Epub ahead of print]. In this 4-year longitudinal study in older adults, scores on the object recognition task, Novel Image Novel Location, detected gradual impairment over time and were correlated with logical memory and word recall as well as clinical dementia rating scales. MMSE scores did not change in these same individuals, indicating greater sensitivity of Novel Image Novel Location.

95. Karantzoulas S, Lau H, Myers CE, et al. Preclinical behavioral detection of Alzheimer's disease. JNHA. 2011;15:S8.

96. • Silverberg N, Ryan L, Carillo M, et al.: Assessment of cognition in early dementia. Alzheimers Dement 2011, 7:e60-e76. This article is a summary of discussions at a meeting convened by the National Institute on Aging and the Alzheimer's Association to discuss state-of-the-art methods for cognitive assessment to detect impairment in the early stages of Alzheimer's disease. Speakers discussed research using novel tests of object recognition, spatial navigation, attentional control, semantic memory, semantic interference prospective memory, false memory, and executive function as cognitive tools to detect prodromal $A D$ and other neurodegenerative diseases.

97. •- Selkoe D, Resolving controversies on the path to Alzheimer's therapeutics. Nat Med 2011, 17:1060-1065. In this "Perspective" article, a leading Alzheimer's disease researcher presents concerns and possible explanations for recent failures in major clinical trials and suggests that these failures do not necessarily predict the future. Trials focusing on the mild or presymptomatic phases of Alzheimer's disease are likely to lead to success in the near future if they use mechanism-based therapeutic agents and assess cardinal cognitive symptoms. 